\title{
Cell - to Species-Level Diversity of Epigenetic Setting for Androgen Receptor Expression in Mammals
}

Masahiro Uesaka and Takuya Imamura

Laboratory for Biodiversity, Global COE program, Department of Biological Science, Graduate School of Science, Kyoto University, Japan

\begin{abstract}
During mammalian development, androgen circulates throughout the body and masculinizes several tissues through endocrinological pathways by binding androgen receptor (AR). At the onset of brain masculinization/defeminization, the androgen-AR system functions in a region-specific manner and, even in adulthood, this system affects the transcription of a certain set of genes. The androgen-AR system, together with several coregulators such as histone modifiers, epigenetically regulates many kinds of genes to express the phenotype of a cell according to the cell's own androgensensitivity as well as the dose of androgen to which it is exposed. Long-range DNA-protein interactions via chromatin looping structures also set up epigenetic regulatory mechanisms that affect the androgen responsiveness. Importantly, the androgen-AR system regulates the transcription of $A R$ itself. For such autoregulation, there are a variety of ciselements within the coding sequences as well as in the regulatory region of $A R$, including multiple androgen response elements. We found that some of these cis-elements diverged across species: among them there are several primatespecific regions and rodent-specific regions including a short interspersed element, called B2 SINE, as shown by comparisons between primates and rodents. These data suggest that the gain and/or loss of cis-elements by deletion, insertion and mutation determines the species-specific regulation of $A R$ transcription. Differences in the sequences of $A R / A r$ regulatory regions may contribute to species-specific transcription regulation in genetic and epigenetic manners. Studies focusing on the biodiversity of the $A R$ regulatory region are important for understanding the diversity of the epigenetic setting determining the responsiveness of cells to androgen.
\end{abstract}

Keywords: Androgen receptor, Epigenetic regulation, Autoregulation, DNA methylation, Pseudogene, Biodiversity

\section{Introduction}

$S R Y$ is a sex-determining gene on the $\mathrm{Y}$ chromosome in eutherians [1]. Certainly, it is SRY which plays the main role in sexual determination of the gonads. During gestation, SRY initiates testis differentiation by activating male-specific transcription factors on autosomes. Although both males and females theoretically have the ability to express androgen receptor (AR) because the responsible gene is located on the $\mathrm{X}$ chromosome, SRY directs generation of the testis, which produces androgen and thereby causes the male-biased androgen production. In this way, the androgen-AR system masculinizes tissues other than testis through endocrinological pathways. In mammals, androgen is produced largely in gonadal tissues and plays important roles in sexdependent development and behavior expression by binding with AR in cell nuclei. For example, testosterone, which is a type of androgen, is primarily secreted by the testes and ovaries, and small amounts are also secreted by the adrenal glands [2]. In both male and female rodents, endocrine disturbance at the fetal and/or postnatal stage irreversibly changes the expression level of genes targeted by androgen-AR [3,4]. Resultant abnormalities of morphology and behavior such as lordosis in males and mounting in females occur after the pubertal stage. This means that genetic differences are not solely responsible for the sexdependent compositions of the cells in the brain and the nature of many behavior patterns. Rather, circulating androgens are required both for development to fully masculinize the brain structure and for masculine behavior in an epigenetic manner. In fact, the $A R$ expression pattern has diverged in mammals [5]. In this review, we summarize the present understanding of transcription regulation by androgen. Especially, cell- to species-level regulation of $A R$ expression and the diversity thereof through genetic and epigenetic mechanisms will be featured.

\section{Quantitative and Qualitative Effects of Androgen on Transcriptional Regulation}

In the testis, androgen functions as a paracrine hormone: it is produced in Leydig cells and acts locally in Sertoli cells in order to support sperm production [6,7]. In addition, fluctuation of the androgen level plays crucial roles in many biological processes in brain and other tissues. For instance, in fetal male rats, the concentration of plasma testosterone dramatically increases up to $\sim 2.2 \mathrm{ng} / \mathrm{ml}$ from day 18 of gestation [8]. This rise is a male-specific feature. After day 18, the plasma concentration of testosterone in fetal males decreases steadily to $\sim 0.7 \mathrm{ng} / \mathrm{ml}$ on day 22 , but on day 23 the level rises again up to $\sim 1.3$ $\mathrm{ng} / \mathrm{ml}$. This transient upregulation of local testosterone concentration, i.e., the "androgen shower", causes the brain masculinization [9]. Another example is that, during testis maturation, the production of luteinizing hormone (LH) and of follicle-stimulating hormone (FSH), which are differentially but significantly affected by androgen [10], increase at an early pubertal stage, followed by genitalia development and spermatogenesis [11,12]. Through adulthood, testosterone, whose serum concentration is kept at $\sim 4.5 \mathrm{ng} / \mathrm{ml}$, maintains the spermatogenesis in combination with FSH in rats [13]. The $A R$ expression level as well as the local concentration of androgen might

*Corresponding author: Takuya Imamura, PhD, DVM, Kitashirakawa-Oiwake Sakyo-ku, Kyoto 606-8502, Japan, Fax +81-75-753-4261; E-mail: imamura@gcoe. biol.sci.kyoto-u.ac.jp

Received August 11, 2011; Accepted October 03, 2011; Published October 05 , 2011

Citation: Uesaka M, Imamura T (2011) Cell - to Species-Level Diversity of Epigenetic Setting for Androgen Receptor Expression in Mammals. J Steroids Hormon Sci S2:004. doi:10.4172/2157-7536.S2-004

Copyright: @ 2011 Uesaka M, et al. This is an open-access article distributed unde the terms of the Creative Commons Attribution License, which permits unrestricted use, distribution, and reproduction in any medium, provided the original author and source are credited. 
be, at least in part, involved in shaping the distinct morphological and physiological features in male and females.

In the adrenal gland, androgen functions as an autocrine and/or a paracrine hormone: the zona fasciculata and zona reticularis contain a large number of AR-positive cells. It is known that adrenal androgen is secreted by the zona reticularis [14]. Dehydroepiandrosterone (DHEA), one of the androgens, is the major secretory steroidal product of the adrenal gland. In humans, the androgen-AR system in adrenal glands also seems to be affected by endocrine pathways, because, for example, chemical castration (administration of luteinizing hormone releasing hormone agonist) causes an increase in LH and FSH levels, which is followed by an increase in the level of adrenal DHEA $[15,16]$.

The sensitivity of cells in the mammalian brain to androgen varies depending on the expression level of $A R$. The expression pattern of $A R$ shows a brain-region-specific pattern. AR-containing neurons are widely distributed, with the greatest densities of such cells in the hypothalamus of male and female rodents [17]. The best examples are the medial preoptic area and ventromedial nuclei (VMN), each of which is thought to play a key role in mediating the hormonal control of copulatory behavior. In the male and female rat brain, significant numbers of AR-positive cells are also found in the lateral septal nucleus, the medial and cortical nuclei of the amygdala, the amygdalohippocampal area, and the bed nucleus of the stria terminalis [17]. The brain-region-specific expression pattern of $A R$ and localization of AR protein in cells are sex-dependent. In the male human brain, the level of AR protein in the cell nuclei is generally higher in neurons of the lateromamillary nucleus, the horizontal limb of the diagonal band of Broca, the diagonal band of Broca, paraventricular nucleus, sexually dimorphic nucleus of the preoptic area, suprachiasmatic nucleus, $\mathrm{VMN}$, infundibular nucleus and the medial mamillary nucleus than that in the corresponding regions of the female brain [18]. In most brain areas of humans, there is more cytoplasmic AR protein in male neurons than female neurons, suggesting that this sex-dependent intracellular localization of AR may also have functional significance.

Depending on their androgen sensitivity, AR-expressing cells undergo various processes such as cell migration, cell proliferation and apoptosis in response to similar doses of dihydrotestosterone (DHT). For example, DHT upregulates AR, cyclin A, cyclin D1, and vascular endothelial growth factor gene expression in a doseand time-dependent manner for the induction of cell proliferation in primary human aortic endothelial cells [19]. In certain prostate cancer cell lines, cell survival and growth are promoted by acetylated and ligand-bound AR [20]. In contrast, $A R$ knockdown by siRNA induces cell growth retardation in a prostate cancer cell line, LNCaP [21]. Androgen can induce apoptosis. Significant decreases in thymic size occur $2-4 \mathrm{~h}$ after testosterone cypionate (TC) is administered to castrated male mice [22]. In this change, TC-induced apoptosis plays a role in modulating the size and composition of the thymus. AR also plays indispensable roles in mitogen-activated protein kinase kinase kinase-1-induced apoptosis in prostate cancer cells [23]. In PC-3(AR)2 cells with stably transfected $A R$, DHT functions in the induction of cell growth inhibition and apoptosis [24]. The tumor suppressor BRCA-1 is also involved in DHT-induced cell death through $A R$ transactivation $[25,26]$. Considering the differential but robust effects of DHT in cells, the epigenetic choice during critical stages, including the timing of androgen-induced brain masculinization, should be important for the differential regulation of AR target genes in cells, and will therefore be further discussed below.

\section{Gradual Effect of Androgen Withdrawal on Cells Through Epigenetic Regulation}

Currently, histone modifications and DNA methylation are known as major players engaged in the mechanism of epigenetic setting in mammals. A wide range of species, including unicellular organisms, utilize histone modification for transcriptional regulation [27]. In contrast, DNA methylation is utilized in a more restricted set of species. In fact, the genome-wide DNA methylation level varies depending on the species: there are only trace amounts of methylcytosine in Drosophila melanogaster [28,29], whereas in mammals, DNA methylation mainly occurs at the cytosine in the $\mathrm{CpG}$ dinucleotide and is utilized as a primary mechanism for generating the cell- and tissuedependent gene expression pattern [30-33]. Because mutations in genes associated with DNA methylation cause many defects in neural systems such as Rett syndrome and ICF syndrome [34-36], DNA methylation should play critical roles in the development of the central nervous system. The DNA methylation system in cells displays robustness; for example, induced pluripotent stem cells generated by using factorbased reprogramming of adult murine tissues harbor residual DNA methylation signatures characteristic of their somatic tissue of origin [37]. Long-term exposure of cells to sex steroid hormones may induce sex-dependent DNA methylation patterns. Indeed, androgen-AR containing complexes consist of many kinds of proteins such as histone modification enzymes, which affect the epigenetic status of target gene promoter regions [38-40]. Moreover, testosterone propionate (TP) or DHT supplementation influences the status of histone modification, nucleosome occupancy and DNA methylation, as discussed in detail later [41-43].

Because of the involvement or lack of involvement of the estrogenER system in the brain masculinization in rodents and primates, respectively [44], we do not yet know if the androgen-AR system is commonly used for epigenetic setting of the brain across species. Indeed, androgen priming of the cells determines the sensitivity of these cells to androgen itself in later stages of life. For example, in adulthood, the concentration of circulating androgen can influence the size of certain brain regions in mammals [45]. In the posterodorsal medial amygdala, neuronal soma size is greater in male rats than in females, and this sexual dimorphism is maintained most probably by circulating androgen. One month after surgical castration of adult males, these brain regions shrunk to a size indistinguishable from that in females without changing the cell number, whereas TP treatment of adult females enlarged these regions to sizes similar to those in males [45]. This response to TP in the adult brain can be regarded as an epigenetic phenomenon because the cells changed their phenotypes without proliferation. If androgen sets a specific epigenetic status, it appears to be difficult to alter it later. This hypothesis is supported by the cell behavior upon androgen withdrawal. Long-term deprivation of DHT or TP from the culture medium of prostate cancer cells can convert some cells to clones that are completely independent of androgen for their cell survival $[46,47]$. Even in these androgen-insensitive cells, CASP8, which is normally upregulated by androgen-AR, is still expressed irrespective of androgen. Similarly, TMS1, which is downregulated by androgen-AR, still keeps its repressed status. These transcription states can be altered by treatment with 5 -aza-2'-deoxycytidine, a drug that alters the DNA methylation pattern [48]. In fact, differences in genome-wide DNA methylation and gene expression profiles have been observed between AR-positive and AR-negative cancer cells. Taken together, these findings suggest that androgen signal primarily maintains the status of the cell physiology, and later can be replaced 
by a more stable mark by which the cell "memorizes" the androgendependent gene expression pattern even in the absence of any steroid hormones.

\section{Effect of Androgen-bound AR on Epigenetic Regulation}

In the cell nucleus, AR dimerizes and binds to a specific sequence known as the androgen response element (ARE). Occupancy of ARE by the androgen receptor complex can lead to the acute upregulation of the physically associated gene [49,50]. Glucocorticoid, mineralocorticoid, and progesterone receptors and AR constitute a group of proteins that form homodimers capable of recognizing three-nucleotidespaced inverted repeats (IR3) nestled between two 5'-TGTTCT-3' $[51,52]$. However, this consensus sequence sometimes does not effectively predict AR-binding regions in androgen target genes [5355]. Therefore, androgen-responsive sequences were further collected experimentally, and it was found that the 3 ' half site of ARE, but not the 5 ' half, was commonly utilized for recognition by liganded AR [56]. In other words, androgen-AR can recognize diverse sequences together with a subset of epigenetic regulators such as methyl-binding proteins and histone modifiers, leading to the differential gene expression depending on the cell [38].

Regarding histone modifiers, CBP/p300 and LSD1, which possess histone acetyltransferase and demethylase activities, respectively, $[57,58]$ seem to function as coactivators together with AR. In vitro studies indicate that androgen-AR is present together with $\mathrm{CBP}$, acetylated histones, and RNA polymerase, on the promoters of active AR- as well as ER-target genes, suggesting that histone acetylation might play an important role together with $\mathrm{AR}$ [59]. In a different context, AR mediates gene repression [60]. A direct protein-protein interaction among 5'TG3' interacting factor (TGIF), AR and a transcription corepressor, $\mathrm{Sin} 3 \mathrm{~A}$, recruits HDAC1 to repress the target gene. In this context, differential utilization of partner proteins of $A R$ depending on the cell may underlie the sequence-specific epigenetic setting. The expression of partner proteins of AR is sex-dependent. For example, the level of CBP in the rat hypothalamus is higher in male than in female neonates. Knockdown of CBP in the hypothalamus of males by antisense oligonucleotides causes behavioral feminization [61]. Regarding DNA methylation, AR could affect the formation of sex-dependent DNA methylation patterns in response to androgen. In the cerebral cortex of mice, amyloid precursor protein $(A p p)$ promoter methylation is higher, and App mRNA expression is lower in females than in males. Treatment with TP decreased the DNA methylation level of the App promoter region [62]. Thus, both DNA methylation and histone modification are involved in epigenetic setting of androgen-AR targets. It should be noted that $A R$ itself is targeted for androgen-mediated DNA methylation pattern regulation in a cellspecific manner. The impact of the auto-regulation by androgen-AR is described in detail below.

In addition to the epigenetic regulators in AR-expressing cells, the tertiary structure made by long-range DNA-protein interactions may also determine the androgen responsiveness. Biochemical and genetic studies have revealed that cooperation between the enhancer and the promoter in a prostate-specific antigen gene results in maximal androgen responsiveness [63-70]. Using the 3C assay, which makes it possible to identify long-range DNA-protein interactions, it was found that both androgen and FOXA1, a major FOX family member [71-73], are required for chromatin looping in LNCaP cells [74]. In this system, Med12, one of the components of the androgen-AR complex, mediates enhancer-promoter looping [75]. Moreover, a similar phenomenon can also be seen in the promoter region of genes targeted by estrogenbound ERa, [76], raising the possibility that looping-structures could perform local transcriptional regulation [77]. In accord with the idea of ERa-mediated epigenetic setting, the androgen-AR system thus appears to be involved in differential chromatin looping that may somehow be fixed for long-range regulation of gene expression (Figure 1). Genes within such a looping-structure showed coordinated upregulation of their transcription by supplementation of steroid hormones. The regions close to the AR-bound regions showed a tendency to rapidly constitute active chromatin structures reminiscent of the active gene transcription in response to androgen. A specific gene cluster might be organized to restrict the epigenetic effects of the androgen-AR complex within a loop to strengthen the coordination of the transcription, and this structure would isolate this effect to prevent leaky transcription of genes located outside of the loop. Such differential AR-triggered epigenetic setting depending on the cell type may account for the tissue- and species-dependent differences of cell fates resulting from various degrees of responsiveness to androgen.

\section{Cell-type-dependent Autoregulation of $A R$}

Figure 2 summarizes the cis-elements that potentially act to generate commonality and inter-cell diversity of the AR expression pattern in human cells. Notably, transcription factors that potentially bind to the cis-elements listed in Figure 2 frequently show cell-typedependent expression patterns within a species. The promoter for $A R$ exhibits a GC-rich character and the absence of a TATA box [78]. This core promoter contains an Sp1 binding site (-46/-37) and helix-loophelix (HLH) protein binding site (-19/-14) [79]. Immediately upstream, there is a long homopurine stretch $(-117 /-60)$ which is important for the AR promoter activity and conserved in rodents and primates. Multiple weak Sp1 binding sites in this homopurine region increase the supply

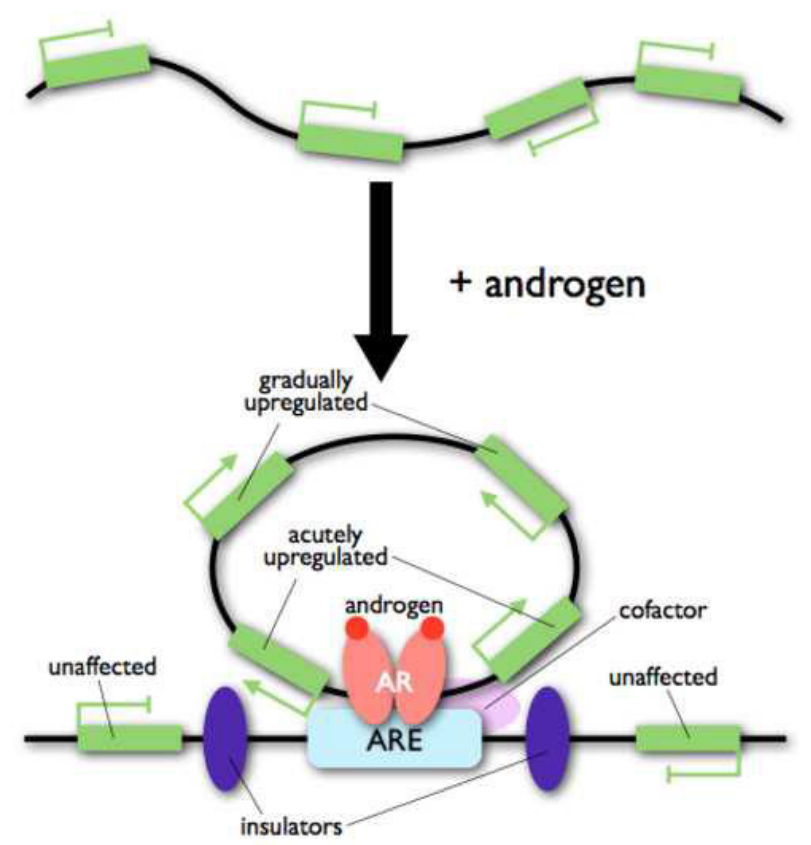

Figure 1: Androgen-dependent tertiary structure resulting from chromatin setting through AR-ARE interactions. In this model, the AR-ARE complex, together with several cofactors, forms a highly ordered chromatin structure. A set of genes within the loop structure are regulated similarly, unlike the genes outside of this loop. Genes proximal to the ARE tend to show rapid upregulation, followed by later expression of distal genes. 


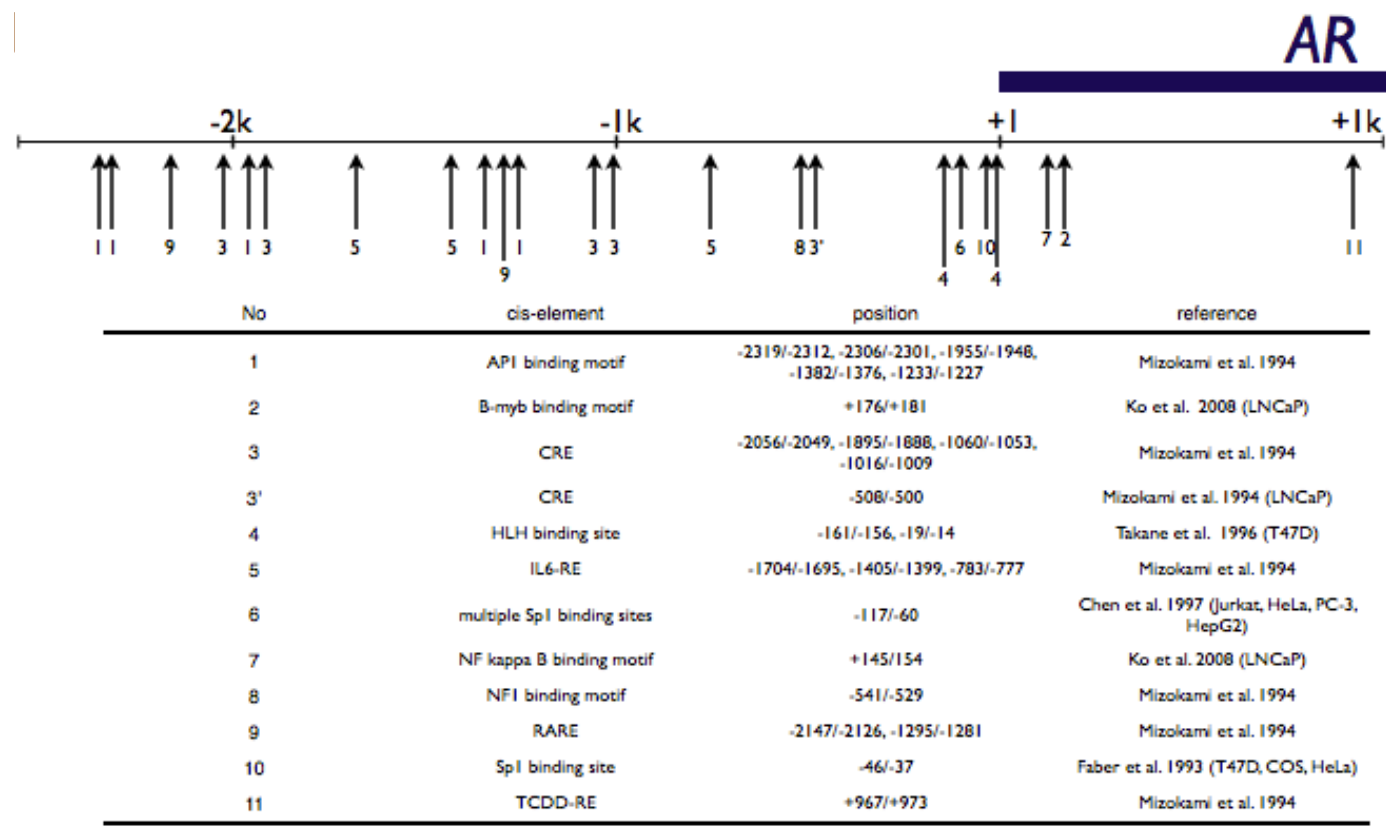

Figure 2: Information about cis-elements around the 5 ' flanking region of human $A R(-2.5 \mathrm{~kb}$ to $+1 \mathrm{~kb}$ relative to TSS). The thick blue line shows the 5 '-untranslated region of $A R$ mRNA. Each arrow represents the relative position of a cis-element with a given identification number corresponding to those listed below the schematic representation of the genomic structure. In cases in which AR binding sites have been experimentally specified, the names of the cells are indicated.

of this transcription factor to the minimal promoter to facilitate the assembly of the transcription initiation complex [80]. In the 5' flanking sequence, there also proved to be binding of NFKB [81,82], B-myb [83], cAMP response element binding protein (CREB) [84], NF1[85] and HLH protein [79]. In addition, the region from the transcription start site (TSS) to $-2.3 \mathrm{~kb}$ contains predicted binding sites for NF1, AP1 and CREB, and also retinoic acid response element (RARE), interleukin-6 responsive element (IL6-RE) and 2,3,7,8-tetrachloro-dibenzo-p-dioxin responsive element (TCDD-RE) sequences [84]. This huge variety of cis-elements enables complex transcriptional regulation via association with trans-acting factors.

Actually, AR itself is a factor involved in the regulation of $A R$ expression. The androgen-AR system could affect $A R$ promoter activity through AR binding to the multiple AREs [86-88]. Reporter assays with the proximal $5^{\prime}$-flanking region of the TSS reproduced this autoinduction by androgen [89]. AREs are also located in exons 4 and 5 of $A R$, spanning $\sim 350 \mathrm{bp}$ of the AR cDNA derived from $\sim 6.5 \mathrm{~kb}$ of the genomic DNA $[90,91]$. This 350-bp region also contains a Myc consensus site where interaction of Myc with Max, a factor dimerizing with Myc and involved in cell fates [92], occurs for androgen regulation [91]. These kinds of autoinduction via the interaction of androgen-AR with multiple AREs occurs in a cell-specific manner, reflecting the cell's sensitivity to androgen. Therefore, it is plausible that the autoregulatory loop for setting androgen-AR sensitivity in cells shares the core circuit regulating the endocrine environment. This hypothesis is supported by the fact that, for example, the 350-bp region is androgen regulated in U2OS and PC3 cells, in which androgen methyltrienolone (R1881) or DHT can induce $A R$ expression [89,93], but not in LNCaP cells, in which R1881 downregulates $A R$ expression [94-96]. Thus, epigenetic regulation by forming specific DNA methylation patterns and tertiary structures may underlie the characteristics of $A R$-expressing cells. Indeed, an ARE located in exon 4, which is $>150 \mathrm{~kb}$ distant from the TSS, could participate in the transcriptional regulation of AR, suggesting that the looping structures help to keep AREs close to the
TSS. Since DNA methylation plays a critical role in the transcription of AR [97-99], it would be interesting to clarify the molecular mechanism governing the epigenetic setting of AR expression by androgen-AR together with factors regulating DNA methylation in a cell-specific manner

\section{Possible Contribution of Species-specific cis-elements for $A R$ to its Transcription}

Studies focusing on the homology of proximal and distal regulatory regions of $A R / A r$ between primates and rodents will lead to better understanding of the species-specific regulation. Differences in the transcriptional regulation of $A R / A r$ between primates and rodents may be responsible for functional divergence of the responses to endocrinological and environmental cues. Actually, the mechanism of brain masculinization/defeminization involving sex-steroid hormones (androgen and estrogen) is different between primates and rodents. Androgens are required to fully masculinize the brain structure during development and the behavior in adulthood. In rodents, estradiol is made by the aromatization of testosterone and interacts with ER for brain masculinization [100]. In contrast, there is little evidence that aromatized metabolites of androgen play this role in primates, including humans $[44,101]$. There are other examples in which androgens themselves also masculinize the brain through their interaction with AR in mice and rats $[44,102,103]$. The brain-regionspecificity of $A R$ expression is also different between primates and rodents [5], perhaps due to species-dependent DNA elements and/ or their epigenetic modifications. Considering that the androgen-AR system triggers brain masculinization in both rodents and primates, the responsiveness of AR expression to estrogen-ER may be different between these orders. This hypothesis is supported by the fact that transcriptional regulation of $A R / A r$ by estrogen differs depending on the species [77]. However, ER-binding sites have not been identified in the $A R / A r$ regulatory regions. Therefore, comparing various features of the species-dependent differences of the $A R$ regulatory 
Citation: Uesaka M, Imamura T (2011) Cell - to Species-Level Diversity of Epigenetic Setting for Androgen Receptor Expression in Mammals. J Steroids Hormon Sci S2:004. doi:10.4172/2157-7536.S2-004

region might be important for understanding the dependence on or independence of estrogen of various biological phenomena, including brain masculinization, in different mammals.

The proximal regulatory region of $A R$ is highly homologous ( $95 \%)$ in the human and macaque genomes. In contrast, the corresponding regions have diversified between the mouse and rat genomes. From the dot plot analysis of the Ar locus in mice and rats, we identified a mousespecific region (-1806 to -1603) in the proximal region of mouse $\mathrm{Ar}$ (Figure 3A). Interestingly, homology search using the BLAST algorithm indicates that this region contains a short interspersed element (SINE), called B2. In the mammalian genome, there are many SINEs, which are propagated by retrotransposition. The $\mathrm{B} 2$ class of the SINE family constitutes approximately $0.7 \%$ of total mouse genomic DNA [104]. The B2 SINE family has the potential to distribute a functional ciselement throughout the genome [105]. For example, the B2 SINE in the promoter region of Lama3 is bound by the transcription factor USF to regulate the gene transcription. The transcription occurring at B2 SINE itself can also shape a given tissue [106]. The B2 SINE

\section{A}
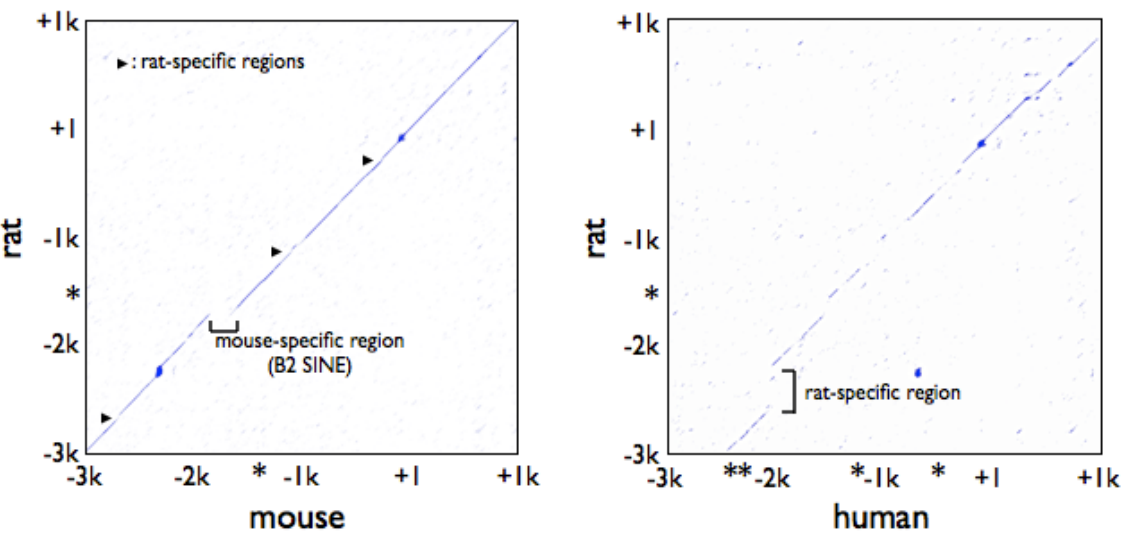

B

proximal regulatory region of $A R / A r$

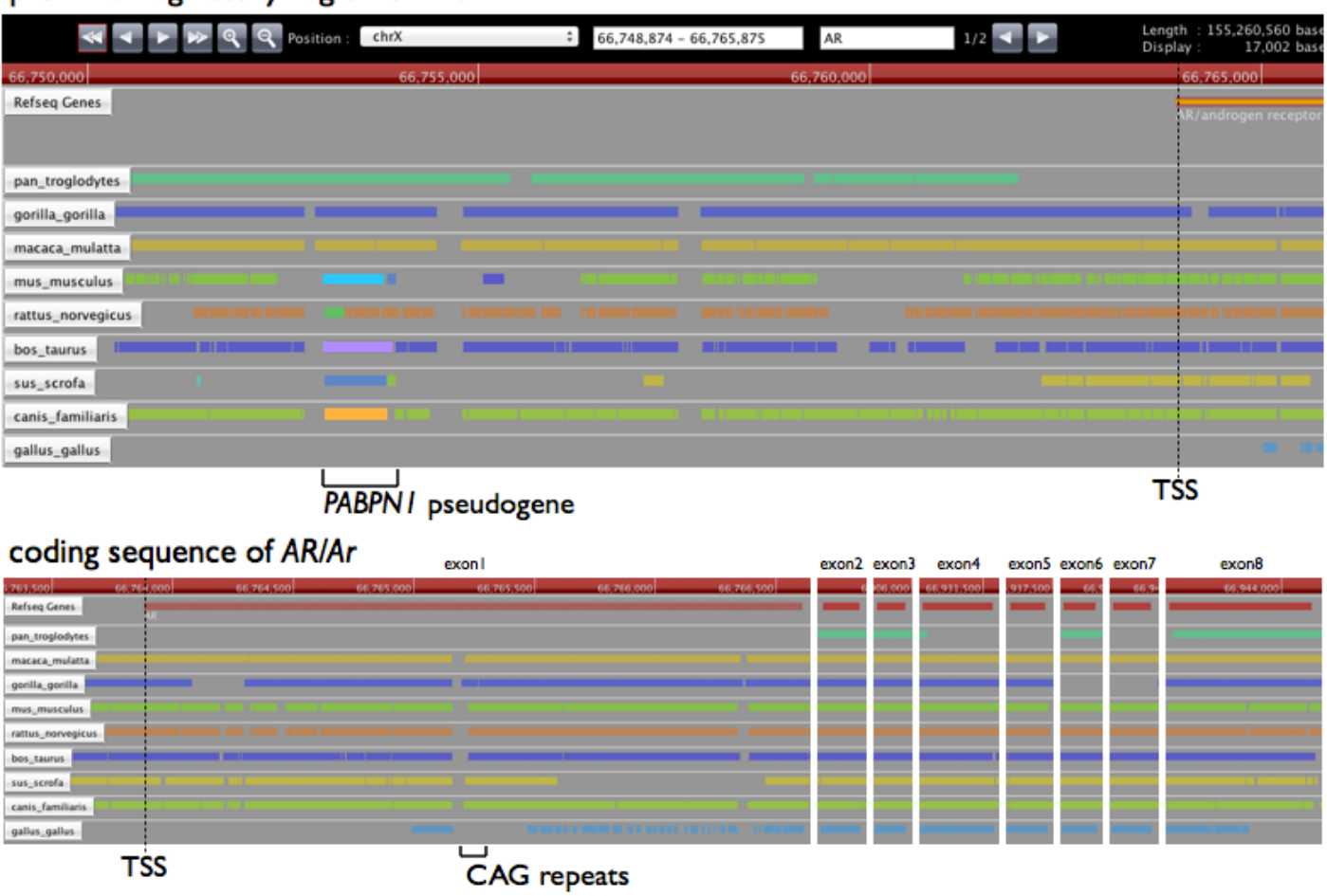

Figure 3: Divergence of the 5'-flanking sequences of $A R / A r$. A. Dot plot of the mouse $A r$ and human $A R$ relative to the rat $A r$ locus. In this plot, sequences with high similarity were plotted in a 50-bp window. B. Sequence comparison of 5 ' region ( $-15 \mathrm{~kb}$ to $+2 \mathrm{~kb})$ and CDS of $A R / A r$ across species using the BLASTZ algorithm. Data were visualized with the software GenomeJACK (http://www.mss.co.jp/businessfield/bioinformatics/solution/products/genomejack/index.html). Each colored bar in the row for the indicated species represents a particular chromosome where the sequence best matched to the human genomic sequence in the red bar is located. Asterisks denote half-sites of consensus estrogen responsive element (5'-GGTCAnnnTGACC-3': [114]). 
transcribed in murine growth hormone-expressing cells regulates the gene expression in a cell-specific manner. At this gene locus, the transcription of B2 SINE functions as a boundary to block the influence of repressive chromatin modifications. Therefore, one can easily speculate that the B2 SINE insertion in the 5'-flanking sequence of $A r$ in mice generates the species-dependent $A r$ regulation by altering the chromatin structure for epigenetic regulation. In addition, the rat proximal regulatory region contains three small specific sequences (-2659 to $-2642,-1150$ to -1133 and -314 to -302 ; arrowheads shown in Figure $3 \mathrm{~A}$ ). Unlike the mouse-specific regions in $A r$, these rat-specific regions do not contain any consensus sequences, and therefore it will be necessary to experimentally identify the factors that mediate their species-dependent regulation of $A r$. In the same way, from the dot plot analysis of the $A R / A r$ locus in humans and rats, we identified a ratspecific region (-2566 to -2186$)$ in the proximal region (Figure $3 \mathrm{~A})$. This element might be inserted into and disrupt a CRE, which may be involved in generating an autoregulatory loop of the androgenAR system. Exon 1 of human AR contains CAG repeats $(+1287$ to + 1388), which are frequently targeted to be expanded up to $\sim 36$ repeats even without any phenotypic abnormality. In disease conditions, the repeats increase to $38 \sim 65$. The CAG repeat expansion is linked with diseases, such as prostate cancer, breast cancer and SBMA [107-109]. The average number of CAG trinucleotide is different between species: 29 in humans, 19 in rats, and 12 in mice. In humans, there is an inverse relationship between CAG repeat length and the expression level of AR [110]. Therefore, the species difference of the CAG repeat number might also influence the divergence of the transcriptional regulation of $A R / A r$.

One example in which the species difference of a cis-element contributes to morphology is a human-specific deletion located $\sim 200$ $\mathrm{kb}$ downstream of the transcription termination site of human $A R$ and

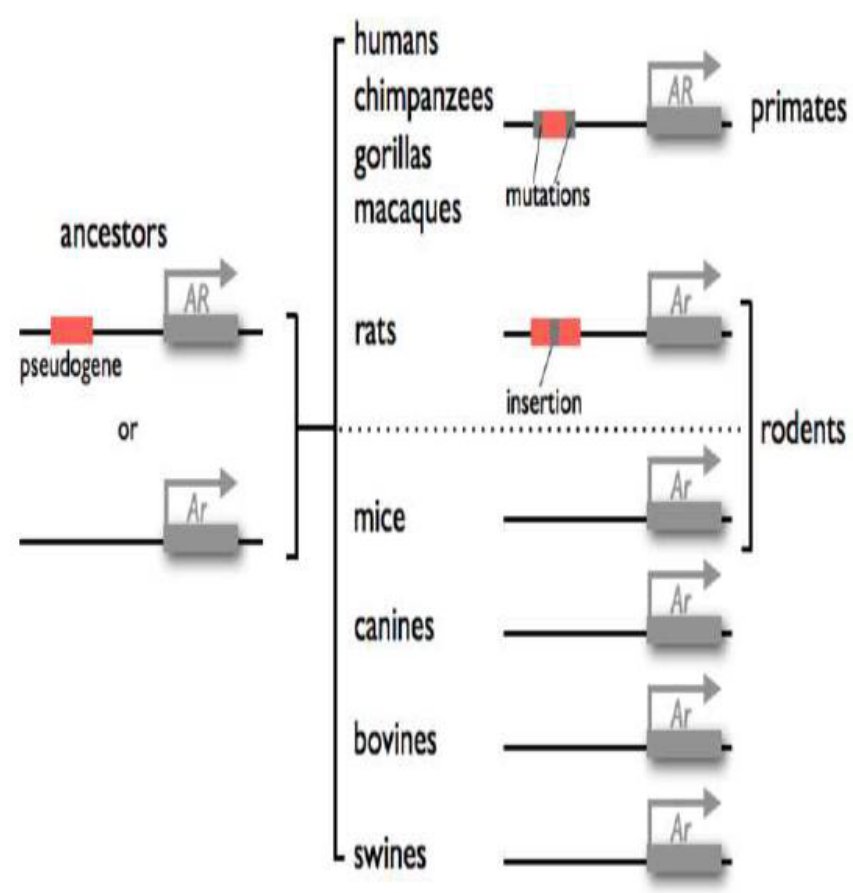

Figure 4: A schematic representation of the proximal regulatory regions of the mammalian AR/Ar. The red bar shows the PABPN1 pseudogene. There are pseudogene-containing and -lacking species, which are separated by a dotted line. spanning $\sim 60 \mathrm{~kb}$. This deletion removes a sensory vibrissae and penile spine enhancer from human $A R$, a molecular change correlated with anatomical loss of androgen-dependent sensory vibrissae and penile spines in the human lineage [111]. Ablation of spines decreases tactile sensitivity and increases the duration of intromission [112]. McLean CY, et al. [111] could not exclude the possibility that loss of the $A R$ enhancer occurred because of relaxed selection following other genetic changes that led to anatomical differences in the human lineage. However, based on the previously established role of AR in vibrissae and penile spine development, the authors hypothesize that deletions of tissue-specific enhancers in $A R$ have contributed to both loss and expansion of particular tissues during human evolution. It is still possible that species differences in the $A R / A r$ regulatory region are the result of genetic drift.

These inter-species comparisons of the proximal regulatory sequences allow us to propose a hypothetical model for the acquisition/ mutation of the pseudogene in the regulatory region of $A R / A r$ during evolution. We compared the proximal regulatory sequences of $A R / A r$ among humans, chimpanzees, gorillas, macaques, mice, rats, bovines, pigs, dogs and chickens (Figure $3 \mathrm{~B}$ ). In primates, a pseudogene for a poly(A) binding protein, nuclear 1 , named $P A B P N 1$, is located there, whereas the corresponding sequence is not found in mice. In rats, bovines, pigs and dogs, there are sequences reminiscent of $P A B P N 1$, but the 5 ' end of this sequence seems to have diverged from that in humans, suggesting the occurrence of retrogene insertion followed by accumulation of mutations in the 5' flanking sequence of $A R / A r$. Nonetheless, an Ensembl transcript (Accession number: ENST00000449099) is well aligned with this divergent DNA element, which may suggest the utilization of this sequence for speciesdependent RNA generation at the $A R / A r$ locus.

Where as mutations in the coding sequence (CDS) may easily cause lethal phenotypes by causing amino acid substitutions, mutations in the regulatory regions might diversify the transcription factor binding, and thereby change the expression level without causing protein structure alterations [113]. Regarding this possibility, we also compared the CDS of $A R / A r$ among humans, chimpanzees, gorillas, macaques, mice, rats, bovines, pigs, dogs and chickens, and found that it is strongly conserved across mammals but not across vertebrates (Figure 3B). Figure 3C shows a summary of the diversity of the $A R / A r$ proximal regulatory regions. Deletion, insertions and the accumulation of mutations may have been positively fixed to confer the observed divergent and species-specific aspects of transcription regulation. The commonality and diversity of the cis-element in the proximal region of mammalian $A R / A r$ described above will be helpful for understanding the species-dependent epigenetic setting for $A R / A r$ transcription.

\section{Concluding Remarks}

AR can be involved in the epigenetic regulation of a subset of genes, including $A R$. Diversified as well as conserved sequences in the 5 '-flanking region of $A R$ seem to be utilized for the epigenetic setting. Here, we emphasize the importance of not only the common aspects of androgen for cell physiology, but also species-specific phenomena, including sexual behavior, that are primarily driven by the genetic differences in the regulatory region of $A R$ affecting its epigenetic setting. These cis-elements appear to be utilized as "epigenetic switches" participating in cell-, tissue-, and/or species-specific regulation with the ability to turn on and/or off the transcription of $A R$ through epigenetic regulation by DNA methylation and histone modifications. 
Citation: Uesaka M, Imamura T (2011) Cell - to Species-Level Diversity of Epigenetic Setting for Androgen Receptor Expression in Mammals. J Steroids Hormon Sci S2:004. doi:10.4172/2157-7536.S2-004

\section{Acknowledgments}

We thank Elizabeth Nakajima for proofreading of this manuscript. Research in the Imamura team is supported by Global COE program A06 of Kyoto University and Grant-in-Aids (Nos. 19040029, and 21688021) from MEXT, Japan and the Asahi Glass Foundation.

\section{References}

1. Wallis MC, Waters PD, Graves JA (2008) Sex determination in mammals-before and after the evolution of SRY. Cell Mol Life Sci 65: 3182-3195

2. Burger HG (2002) Androgen production in women. Fertil steril 4: S3-5

3. Akingbemi BT, Ge RS, Klinefelter GR, Zirkin BR, Hardy MP (2004) Phthalateinduced Leydig cell hyperplasia is associated with multiple endocrine disturbances. Proc Natl Acad Sci U S A 101: 775-780.

4. Foecking EM, Szabo M, Schwartz NB, Levine JE (2005) Neuroendocrine consequences of prenatal androgen exposure in the female rat: absence of luteinizing hormone surges, suppression of progesterone receptor gene expression, and acceleration of the gonadotropin-releasing hormone pulse generator. Biol Reprod 72: 1475-1483.

5. Clancy AN, Bonsall RW, Michael RP (1992) Immunohistochemical labeling of androgen receptors in the brain of rat and monkey. Life sci 50: 409-417.

6. Cunningham GR, Huckins C (1979) Persistence of complete spermatogenesis in the presence of low intratesticular concentrations of testosterone. Endocrinology 105: 177-186.

7. Chang C, Chen YT, Yeh SD, Xu Q, Wang RS, et al. (2004) Infertility with defective spermatogenesis and hypotestosteronemia in male mice lacking the androgen receptor in Sertoli cells. Proc Natl Acad Sci USA 101: 6876-6881.

8. Weisz J, Ward IL (1980) Plasma Testosterone and Progesterone Titers of Pregnant Rats, Their Male and Female Fetuses, and Neonatal Offspring. Endocrinology 106: 306-316.

9. Schulz KM, Richardson HN, Zehr JL, Osetek AJ, Menard TA, et al. (2004) Gonadal hormones masculinize and defeminize reproductive behaviors during puberty in the male Syrian hamster. Horm Behav 45: 242-249.

10. Shaar CJ, Euker JS, Riegle GD, Meites J (1975) Effects of Castration and Gonadal Steroids on Serum Luteinizing-Hormone and Prolactin in Old and Young-Rats. J Endocrinol 66: 45-51.

11. de Kretser DM, Loveland KL, Meinhardt A, Simorangkir D, Wreford N (1998) Spermatogenesis. Hum Reprod 1: 1-8

12. Steinberger E (1971) Hormonal control of mammalian spermatogenesis. Physiol Rev 51: 1-22.

13. Bartlett JMS, Weinbauer GF, Nieschlag E (1989) Differential-Effects of Fsh and Testosterone on the Maintenance of Spermatogenesis in the Adult Hypophysectomized Rat. J Endocrinol 121: 49-58.

14. Takeda H, Chodak G, Mutchnik S, Nakamoto T, Chang C (1990) Immunohistochemical localization of androgen receptors with mono- and polyclonal antibodies to androgen receptor. J Endocrinol 126: 17-25

15. Berger CC, Bokemeyer C, Schuppert F, Schmoll HJ (1996) Endocrinological late effects after chemotherapy for testicular cancer. BrJ Cancer 73: 11081114.

16. Oka H, Negoro H, Sugino Y, Iwamura H, Moroi S, et al. (2003) Change of serum adrenal androgens in prostatic cancer patients after bilateral orchidectomy or LHRH agonist treatment. Hinyokika Kiyo 49: 521-525.

17. Simerly RB, Chang C, Muramatsu M, Swanson LW (1990) Distribution of androgen and estrogen receptor mRNA-containing cells in the rat brain: an in situ hybridization study. J Comp Neurol 294: 76-95.

18. Fernandez-Guasti A, Kruijver FP, Fodor M, Swaab DF (2000) Sex differences in the distribution of androgen receptors in the human hypothalamus. J Comp Neurol 425: 422-435.

19. Cai J, Hong Y, Weng C, Tan C, Imperato-McGinley J, et al. (2011) Androgen stimulates endothelial cell proliferation via an androgen receptor/VEGF/cyclin A-mediated mechanism. Am J Physiol Heart Circ Physiol 300: 210-221.

20. Fu M, Rao M, Wang C, Sakamaki T, Wang J, et al. (2003) Acetylation of androgen receptor enhances coactivator binding and promotes prostate cance cell growth. Mol Cell Biol 23: 8563-8575.
21. Haag P, Bektic J, Bartsch G, Mocker H, Eder IE (2005) Androgen receptor down regulation by small interference RNA induces cell growth inhibition in androgen sensitive as well as in androgen independent prostate cancer cells. J Steroid Biochem Mol Biol 96: 251-258.

22. Olsen NJ, Viselli SM, Fan J, Kovacs WJ (1998) Androgens accelerate thymocyte apoptosis. Endocrinology 139: 748-752.

23. Abreu-Martin MT, Chari A, Palladino AA, Craft NA, Sawyers CL (1999) Mitogen-activated protein kinase kinase kinase 1 activates androgen receptordependent transcription and apoptosis in prostate cancer. Mol Cell Biol 19: 5143-5154.

24. Heisler LE, Evangelou A, Lew AM, Trachtenberg J, Elsholtz HP, et al. (1997) Androgen-dependent cell cycle arrest and apoptotic death in PC-3 prostatic cell cultures expressing a full-length human androgen receptor. Mol Cell Endocrinol 126: 59-73.

25. Yeh S, Hu YC, Rahman M, Lin HK, Hsu CL, et al. (2000) Increase of androgeninduced cell death and androgen receptor transactivation by BRCA1 in prostate cancer cells. Proc Natl Acad Sci U S A 97: 11256-11261.

26. Park JJ, Irvine RA, Buchanan G, Koh SS, Park JM, et al. (2000) Breast cancer susceptibility gene 1 (BRCA1) is a coactivator of the androgen receptor. Cancer Res 60: 5946-5949.

27. Jenuwein T, Allis CD (2001) Translating the histone code. Science 293: $1074-$ 1080.

28. Kunert N, Marhold J, Stanke J, Stach D, Lyko F (2003) A Dnmt2-like protein mediates DNA methylation in Drosophila. Development 130: 5083-5090.

29. Lyko F, Ramsahoye BH, Jaenisch R (2000) DNA methylation in Drosophila melanogaster. Nature 408: 538-540.

30. Futscher BW, Oshiro MM, Wozniak RJ, Holtan N, Hanigan CL, et al. (2002) Role for DNA methylation in the control of cell type specific maspin expression. Nat Genet 31: 175-179.

31. Kafri T, Ariel M, Brandeis M, Shemer R, Urven L, et al. (1992) Developmental pattern of gene-specific DNA methylation in the mouse embryo and germ line. Genes Dev 6: 705-714.

32. Shiota K, Kogo Y, Ohgane J, Imamura T, Urano A, et al. (2002) Epigenetic marks by DNA methylation specific to stem, germ and somatic cells in mice. Genes Cells 7: 961-969.

33. Imamura T, Ohgane J, Ito S, Ogawa T, Hattori N, et al. (2001) CpG island of rat sphingosine kinase-1 gene: tissue-dependent DNA methylation status and multiple alternative first exons. Genomics 76: 117-125.

34. Amir RE, Van den Veyver IB, Wan M, Tran CQ, Francke U, et al. (1999) Rett syndrome is caused by mutations in X-linked MECP2, encoding methyl-CpGbinding protein 2. Nat Genet 23: 185-188.

35. Hansen RS, Wijmenga C, Luo P, Stanek AM, Canfield TK, et al. (1999) The DNMT3B DNA methyltransferase gene is mutated in the ICF immunodeficiency syndrome. Proc Natl Acad Sci USA 96: 14412-14417.

36. Xu GL, Bestor TH, Bourc'his D, Hsieh CL, Tommerup N, et al. (1999) Chromosome instability and immunodeficiency syndrome caused by mutations in a DNA methyltransferase gene. Nature 402: 187-191.

37. Kim K, Doi A, Wen B, Ng K, Zhao R, et al. (2010) Epigenetic memory in induced pluripotent stem cells. Nature 467: 285-290.

38. Heinlein CA, Chang C (2002) Androgen receptor (AR) coregulators: an overview. Endocr Rev 23: 175-200.

39. Kang Z, Janne OA, Palvimo JJ (2004) Coregulator recruitment and histone modifications in transcriptional regulation by the androgen receptor. Mol Endocrinol 18: 2633-2648.

40. Lee DY, Northrop JP, Kuo MH, Stallcup MR (2006) Histone H3 lysine 9 methyltransferase $\mathrm{G} 9 \mathrm{a}$ is a transcriptional coactivator for nuclear receptors. J Biol Chem 281: 8476-8485

41. Kumar RC, Thakur MK (2004) Sex steroids reduce DNasel accessibility of androgen receptor promoter in adult male mice brain. Brain Res Mol Brain Res 131: $1-7$.

42. He HH, Meyer CA, Shin H, Bailey ST, Wei G, et al. (2010) Nucleosome dynamics define transcriptional enhancers. Nat Genet 42: 343-347.

43. Sasaki M, Oh BR, Dharia A, Fujimoto S, Dahiya R (2000) Inactivation of the 
Citation: Uesaka M, Imamura T (2011) Cell - to Species-Level Diversity of Epigenetic Setting for Androgen Receptor Expression in Mammals. J Steroids Hormon Sci S2:004. doi:10.4172/2157-7536.S2-004

human androgen receptor gene is associated with CpG hypermethylation in uterine endometrial cancer. Mol Carcinog 29: 59-66.

44. Cooke B, Hegstrom CD, Villeneuve LS, Breedlove SM (1998) Sexua differentiation of the vertebrate brain: principles and mechanisms. Front Neuroendocrinol 19: 323-362.

45. Morris JA, Jordan CL, Breedlove SM (2008) Sexual dimorphism in neuronal number of the posterodorsal medial amygdala is independent of circulating androgens and regional volume in adult rats. J Comp Neurol 506: 851-859.

46. Bruchovsky N, Rennie PS, Coldman AJ, Goldenberg SL, To M, et al. (1990) Effects of androgen withdrawal on the stem cell composition of the Shionogi carcinoma. Cancer Res 50: 2275-2282.

47. Isaacs JT, Coffey DS (1981) Adaptation versus selection as the mechanism responsible for the relapse of prostatic cancer to androgen ablation therapy as studied in the Dunning R-3327-H adenocarcinoma. Cancer Res 41: 5070-5075.

48. Mishra DK, Chen Z, Wu Y, Sarkissyan M, Koeffler HP, et al. (2010) Globa methylation pattern of genes in androgen-sensitive and androgen-independent prostate cancer cells. Mol Cancer Ther 9: 33-45.

49. Verrijdt G, Haelens A, Claessens F (2003) Selective DNA recognition by the androgen receptor as a mechanism for hormone-specific regulation of gene expression. Mol Genet Metab 78: 175-185.

50. Dehm SM, Tindall DJ (2006) Molecular regulation of androgen action in prostate cancer. J Cell Biochem 99: 333-344.

51. Beato M (1989) Gene regulation by steroid hormones. Cell 56: 335-344.

52. Cato AC, Ponta H, Herrlich P (1992) Regulation of gene expression by steroid hormones. Prog Nucleic Acid Res Mol Biol 43: 1-36.

53. Magee JA, Chang LW, Stormo GD, Milbrandt J (2006) Direct, androgen receptor-mediated regulation of the FKBP5 gene via a distal enhancer element. Endocrinology 147: 590-598.

54. Horie-Inoue K, Takayama K, Bono HU, Ouchi Y, Okazaki Y, et al. (2006) Identification of novel steroid target genes through the combination of bioinformatics and functional analysis of hormone response elements. Biochem Biophys Res Commun 339: 99-106.

55. Masuda K, Werner T, Maheshwari S, Frisch M, Oh S, et al. (2005) Androgen receptor binding sites identified by a GREF GATA model. J Mol Biol 353: 763771.

56. Jiang M, Ma Y, Chen C, Fu X, Yang S, et al. (2009) Androgen-responsive gene database: integrated knowledge on androgen-responsive genes. Mol Endocrinol 23: 1927-1933.

57. Baek SH, Ohgi KA, Nelson CA, Welsbie D, Chen C, et al. (2006) Ligandspecific allosteric regulation of coactivator functions of androgen receptor in prostate cancer cells. Proc Natl Acad Sci USA 103: 3100-3105.

58. Kahl P, Gullotti L, Heukamp LC, Wolf S, Friedrichs N, et al. (2006) Androgen receptor coactivators lysine-specific histone demethylase 1 and four and a half LIM domain protein 2 predict risk of prostate cancer recurrence. Cancer Res 66: 11341-11347

59. Shang Y, Myers M, Brown M (2002) Formation of the androgen receptor transcription complex. Mol Cell 9: 601-610.

60. Sharma M, Sun Z (2001) 5'TG3' interacting factor interacts with Sin3A and represses AR-mediated transcription. Mol Endocrinol 15: 1918-1928.

61. Auger AP, Perrot-Sinal TS, Auger CJ, Ekas LA, Tetel MJ, et al. (2002) Expression of the nuclear receptor coactivator, cAMP response elementbinding protein, is sexually dimorphic and modulates sexual differentiation of neonatal rat brain. Endocrinology 143: 3009-3016.

62. Mani ST, Thakur MK (2006) In the cerebral cortex of female and male mice, amyloid precursor protein (APP) promoter methylation is higher in females and differentially regulated by sex steroids. Brain Res 1067: 43-47.

63. Pang S, Dannull J, Kaboo R, Xie Y, Tso CL, et al. (1997) Identification of a positive regulatory element responsible for tissue-specific expression of prostate-specific antigen. Cancer Res 57: 495-499.

64. Pang S, Taneja S, Dardashti K, Cohan P, Kaboo R, et al. (1995) Prostate tissue specificity of the prostate-specific antigen promoter isolated from a patient with prostate cancer. Hum Gene Ther 6: 1417-1426.

65. Huang W, Shostak Y, Tarr P, Sawyers C, Carey M (1999) Cooperative assembly of androgen receptor into a nucleoprotein complex that regulates the prostate-specific antigen enhancer. J Biol Chem 274: 25756-25768.

66. Zhang S, Murtha PE, Young CY (1997) Defining a functional androgen responsive element in the 5' far upstream flanking region of the prostatespecific antigen gene. Biochem Biophys Res Commun 231: 784-788.

67. Sun Z, Pan J, Balk SP (1997) Androgen receptor-associated protein complex binds upstream of the androgen-responsive elements in the promoters of human prostate-specific antigen and kallikrein 2 genes. Nucleic Acids Res 25 3318-3325.

68. Schuur ER, Henderson GA, Kmetec LA, Miller JD, Lamparski HG, et al. (1996 Prostate-specific antigen expression is regulated by an upstream enhancer. $J$ Biol Chem 271: 7043-7051.

69. Reid KJ, Hendy SC, Saito J, Sorensen P, Nelson CC (2001) Two classes of androgen receptor elements mediate cooperativity through allosteric interactions. J Biol Chem 276: 2943-2952.

70. Cleutjens KB, vanderKorput $\mathrm{HA}$, vanEekelen $\mathrm{CC}$, vanRooij $\mathrm{HC}$, Faber PW, et al. (1997) An androgen response element in a far upstream enhancer region is essential for high, androgen-regulated activity of the prostate-specific antigen promoter. Mol Endocrinol 11: 148-161.

71. Lupien M, Eeckhoute J, Meyer CA, Wang QB, Zhang Y, et al. (2008) FoxA1 translates epigenetic signatures into enhancer-driven lineage-specific transcription. Cell 132: 958-970.

72. Gao N, Ishii K, Mirosevich J, Kuwajima S, Oppenheimer SR, et al. (2005) Forkhead box $\mathrm{A} 1$ regulates prostate ductal morphogenesis and promotes epithelial cell maturation. Development 132: 3431-3443.

73. Mirosevich J, Gao N, Matusik RJ (2005) Expression of Foxa transcription factors in the developing and adult murine prostate. Prostate 62: 339-352.

74. Wang D, Garcia-Bassets I, Benner C, Li W, Su X, et al. (2011) Reprogramming transcription by distinct classes of enhancers functionally defined by eRNA Nature 474: 390-394.

75. Kagey MH, Newman JJ, Bilodeau S, Zhan Y, Orlando DA, et al. (2010) Mediator and cohesin connect gene expression and chromatin architecture. Nature 467: 430-435.

76. Fullwood MJ, Liu MH, Pan YF, Liu J, Xu H, et al. (2009) An oestrogen-receptoralpha-bound human chromatin interactome. Nature 462: 58-64.

77. Imamura T (2011) Epigenetic setting for long-term expression of estrogen receptor alpha and androgen receptor in cells. Horm Behav 59: 345-352.

78. Faber PW, van Rooij HC, Schipper HJ, Brinkmann AO, Trapman J (1993) Two different, overlapping pathways of transcription initiation are active on the TATA-less human androgen receptor promoter. The role of Sp1. J Biol Chem 268: 9296-9301.

79. Takane KK, McPhaul MJ (1996) Functional analysis of the human androgen receptor promoter. Mol Cell Endocrinol 119: 83-93.

80. Chen S, Supakar PC, Vellanoweth RL, Song CS, Chatterjee B, et al. (1997) Functional role of a conformationally flexible homopurine/homopyrimidine domain of the androgen receptor gene promoter interacting with Sp1 and a pyrimidine single strand DNA-binding protein. Mol Endocrinol 11: 3-15.

81. Supakar PC, Jung MH, Song CS, Chatterjee B, Roy AK (1995) Nuclear Factor Kappa-B Functions as a Negative Regulator for the Rat Androgen Receptor Gene and Nf-Kappa-B Activity Increases during the Age-Dependent Desensitization of the Liver. J Biol Chem 270: 837-842.

82. Zhang L, Charron M, Wright WW, Chatterjee B, Song CS, et al. (2004) Nuclear factor-kappaB activates transcription of the androgen receptor gene in Sertol cells isolated from testes of adult rats. Endocrinology 145: 781-789.

83. Ko S, Shi L, Kim S, Song CS, Chatterjee B (2008) Interplay of nuclear factorkappaB and B-myb in the negative regulation of androgen receptor expression by tumor necrosis factor alpha. Mol Endocrinol 22: 273-286.

84. Mizokami A, Yeh SY, Chang C (1994) Identification of 3',5'-cyclic adenosine monophosphate response element and other cis-acting elements in the human androgen receptor gene promoter. Mol Endocrinol 8: 77-88.

85. Song CS, Jung MH, Supakar PC, Chatterjee B, Roy AK (1999) Negative regulation of the androgen receptor gene promoter by NFI and an adjacently located multiprotein-binding site. Mol Endocrinol 13: 1487-1496.

86. Iwai M, Kanzaki H, Fujimoto M, Kojima K, Hatayama H, et al. (1995) Regulation 
Citation: Uesaka M, Imamura T (2011) Cell - to Species-Level Diversity of Epigenetic Setting for Androgen Receptor Expression in Mammals. J Steroids Hormon Sci S2:004. doi:10.4172/2157-7536.S2-004

of sex steroid receptor gene expression by progesterone and testosterone in cultured human endometrial stromal cells. J Clin Endocrinol Metab 80: 450454.

87. Loos S, Schulz KD, Hackenberg R (1999) Regulation of GCDFP-15 expression in human mammary cancer cells. Int J Mol Med 4: 135-140.

88. Nakano K, Fukabori Y, Itoh N, Lu W, Kan M, et al. (1999) Androgen-stimulated human prostate epithelial growth mediated by stromal-derived fibroblast growth factor-10. Endocr J 46: 405-413.

89. Wiren KM, Zhang X, Chang C, Keenan E, Orwoll ES (1997) Transcriptional up-regulation of the human androgen receptor by androgen in bone cells. Endocrinology 138: 2291-2300.

90. Dai JL, Burnstein KL (1996) Two androgen response elements in the androgen receptor coding region are required for cell-specific up-regulation of receptor messenger RNA. Mol Endocrinol 10: 1582-1594.

91. Grad JM, Dai JL, Wu S, Burnstein KL (1999) Multiple androgen response elements and a Myc consensus site in the androgen receptor (AR) coding region are involved in androgen-mediated up-regulation of AR messenger RNA. Mol Endocrinol 13: 1896-1911.

92. Amati B, Land H (1994) Myc-Max-Mad: a transcription factor network controlling cell cycle progression, differentiation and death. Curr Opin Genet Dev 4: 102-108.

93. Dai JL, Maiorino CA, Gkonos PJ, Burnstein KL (1996) Androgenic up-regulation of androgen receptor cDNA expression in androgen-independent prostate cancer cells. Steroids 61: 531-539.

94. Quarmby VE, Yarbrough WG, Lubahn DB, French FS, Wilson EM (1990) Autologous down-Regulation of Androgen Receptor Messenger-RibonucleicAcid. Mol Endocrinol 4: 22-28.

95. Wolf DA, Herzinger T, Hermeking H, Blaschke D, Horz W (1993) Transcriptiona and posttranscriptional regulation of human androgen receptor expression by androgen. Mol Endocrinol 7: 924-936.

96. Blok LJ, Themmen AP, Peters AH, Trapman J, Baarends WM, et al. (1992) Transcriptional regulation of androgen receptor gene expression in Sertoli cells and other cell types. Mol Cell Endocrinol 88: 153-164.

97. Jarrard DF, Kinoshita H, Shi Y, Sandefur C, Hoff D, et al. (1998) Methylation of the androgen receptor promoter $\mathrm{CpG}$ island is associated with loss of androgen receptor expression in prostate cancer cells. Cancer Res 58: 5310-5314.

98. Takahashi S, Inaguma S, Sakakibara M, Cho YM, Suzuki S, et al. (2002) DNA methylation in the androgen receptor gene promoter region in rat prostate cancers. Prostate 52: 82-88.

99. Sasaki M, Tanaka Y, Perinchery G, Dharia A, Kotcherguina I, et al. (2002) Methylation and inactivation of estrogen, progesterone, and androgen receptors in prostate cancer. J Natl Cancer Inst 94: 384-390.
100. Thompson EA, Siiteri PK (1974) Utilization of oxygen and reduced nicotinamide adenine dinucleotide phosphate by human placental microsomes during aromatization of androstenedione. J Biol Chem 249: 5364-5372.

101. MacLusky NJ, Naftolin F (1981) Sexual differentiation of the central nervous system. Science 211: 1294-1302.

102. Breedlove SM (1997) Neonatal androgen and estrogen treatments masculinize the size of motoneurons in the rat spinal nucleus of the bulbocavernosus. Cell Mol Neurobiol 17: 687-697.

103. Sato T, Matsumoto T, Kawano H, Watanabe T, Uematsu Y, et al. (2004) Brain masculinization requires androgen receptor function. Proc Natl Acad Sci U S A101: 1673-1678.

104. Bennett KL, Hill RE, Pietras DF, Woodworthgutai M, Kanehaas C, et al. (1984) Most Highly Repeated Dispersed DNA Families in the Mouse Genome. Mol Cell Biol 4: 1561-1571.

105. Ferrigno O, Virolle T, Djabari Z, Ortonne JP, White RJ, et al. (2001) Transposable B2 SINE elements can provide mobile RNA polymerase I promoters. Nat Genet 28: 77-81.

106. Lunyak VV, Prefontaine GG, Nunez E, Cramer T, Ju BG, et al. (2007) Developmentally regulated activation of a SINE B2 repeat as a domain boundary in organogenesis. Science 317: 248-251.

107. Giovannucci E, Stampfer MJ, Krithivas K, Brown M, Brufsky A, et al. (1997) The CAG repeat within the androgen receptor gene and its relationship to prostate cancer. Proc Natl Acad Sci USA 94: 3320-3323.

108. Rebbeck TR, Kantoff PW, Krithivas K, Neuhausen S, Blackwood MA, et al. (1999) Modification of BRCA1-associated breast cancer risk by the polymorphic androgen-receptor CAG repeat. Am J Hum Genet 64: 1371-1377.

109. Sulek A, Hoffman-Zacharska D, Krysa W, Szirkowiec W, Fidzianska E, et al. (2005) CAG repeat polymorphism in the androgen receptor (AR) gene of SBMA patients and a control group. J Appl Genet 46: 237-239.

110. Choong CS, Kemppainen JA, Zhou ZX, Wilson EM (1996) Reduced androgen receptor gene expression with first exon CAG repeat expansion. Mo Endocrinol 10: 1527-1535

111. McLean CY, Reno PL, Pollen AA, Bassan Al, Capellini TD, et al. (2011) Human-specific loss of regulatory DNA and the evolution of human-specific traits. Nature 471: 216-219.

112. Dixson AF (1998) Primate Sexuality: Comparative Studies of the Prosimians, Monkeys, Apes and Human Beings.

113. Carroll SB (2008) Evo-devo and an expanding evolutionary synthesis: a genetic theory of morphological evolution. Cell $134: 25-36$

114. Klein-Hitpass L, Schorpp M, Wagner U, Ryffel GU (1986) An estrogenresponsive element derived from the 5' flanking region of the Xenopus vitellogenin A2 gene functions in transfected human cells. Cell 46: 1053-1061.
This article was originally published in a special issue, Androgen Receptors handled by Editor(s). Dr. Rebecca L Cunningham, University of North Texas Health Science Center, USA; Dr. Ze-hua Liu, Osaka City University, Japan 